\title{
Una revisión de la censura en la Literatura Infantil y Juvenil (LIJ) traducida del inglés en España desde la etapa franquista a la actualidad
}

\author{
Roberto Martínez Mateo \\ Universidad de Castilla La-Mancha \\ roberto.martinez@uclm.es
}

\begin{abstract}
Resumen: Este artículo analiza la evolución de las medidas y consecuencias de la censura aplicada a la Literatura Infantil y Juvenil (LIJ) procedente del inglés vía traducción en la dictadura de Franco, en la etapa de post-guerra y en la actualidad. El escaso valor literario habitualmente atribuido a esta literatura dirigida a los más pequeños la convierte precisamente en un objetivo más vulnerable a los vaivenes del dictamen del que ostenta la autoridad. Además, se trata de una parcela infrainvestigada en el panorama literario español. La revisión contrastiva de varias obras traducidas en diferentes momentos permite ejemplificar los hitos más destacados por los que ha pasado la censura ejercida sobre la LIJ desde el régimen franquista hasta la actualidad.
\end{abstract}

Palabras clave: censura; Literatura Infantil y Juvenil (LIJ); traducción; dictadura.

Abstract: This paper reviews the evolution of censorship's measures and outcomes exerted over Children and Juvenile Literature (CJL) translated from English from the outset of Spanish dictatorship, during the post-war and in present times. The scant literary value usually assigned to this literature aimed at children turns it into a more vulnerable target to the fluctuations in opinion of the rulers. Besides, translated children literature is an under-researched area in Spanish literature. The contrastive analysis of some translations proposals made at different times serves to exemplify the most outstanding milestones which censorship evolution has undergone from Franco's regime up to date.

Keywords: censorship; Children and Juvenile Literature (CJL); translation; dictatorship.

\ Martínez Mateo, Roberto. 2015. "Una revisión de la censura en la Literatura Infantil y Juvenil (LIJ) traducida del inglés en España desde la etapa franquista a la actualidad". Quaderns de Filologia: Estudis Literaris XX: 163-182. doi: 10.7203/ qdfed.20.7535 



\section{Caracterización de la Literatura Infantil y Juvenil}

Abordar la definición de Literatura Infantil y Juvenil (LIJ) es problemático debido, especialmente, a la dificultad de acotar dos elementos clave: el destinatario y la caracterización de la obra en sí. En buena medida debido a que son nociones cuya delimitación dependen del canon literario y la visión del destinatario de cada época.

Respecto al destinatario, muchos consideran que este género literario está exclusivamente dirigido al público infantil y juvenil y hablan de una literatura escrita para niños (Pascua, 2011: 19) y otros defienden la existencia de un doble destinatario (niño-adulto) (Fernández, 1996: 30). En este último público objetivo se incluye al adulto: i) cuando actúa como intermediario para filtrar las lecturas de los niños; ii) cuando la LIJ es utilizada por algunos autores para transmitir mensajes que superan las fronteras del público infantil y aspiran también a calar en el lector adulto. Íntimamente ligado al destinatario está la intencionalidad del autor en el mensaje que transmite que, en la LIJ si cabe más que el resto de la literatura, ha de tenerse especialmente presente (Díaz Armas, 2005: 201).

Otra cuestión relacionada con la caracterización de la LIJ, que suscita un gran debate, es el estatus que se le atribuye y, de ahí, si realmente ocupa una parcela periférica dentro del polisistema ${ }^{1}$ literario de una cultura (Shavit, 1986: 111). Esa concepción polisistémica permite a Even-Zohar argumentar que es posible estudiar la organización de una literatura determinada, de las normas y modelos que la rigen, por medio de la función que desempeñan (el sistema) de las traducciones dentro de polisistema. Incluso va más allá al afirmar que el estudio de la literatura traducida permite detectar el grado en que se producen los contactos entre sistemas literarios y en qué medida condicionan su respectivas evoluciones y así reconocer los procesos de canonización, integración, exclusión, etc.

Ahora bien, sobre lo que sí existe cierta unanimidad acerca de la LIJ, es que estas obras suelen acomodarse a la idiosincrasia del joven lector. Por ello, estas obras suelen adecuar el lenguaje, el argumento y

\footnotetext{
${ }^{1}$ La Teoría del Polisistema, desarrollada por Itamar Even-Zohar (1979), plantea que la literatura está formada por un conjunto de sistemas que se interseccionan, donde existe uno central y varios periféricos, y entre los que se establecen una serie de relaciones de carácter dinámico y heterogéneo.
} 
la caracterización de los personajes para que resulten adecuados y útiles para su público objetivo de acuerdo con lo que la sociedad a la que se dirige considere "bueno para el niño" (Shavit, 1986: 112). La competencia lectora limitada y circunscrita a un escaso bagaje lector perfila un destinatario concreto de corta edad para el que se trata de facilitar la lectura (Puurtinen, 1989: 210)

Posiblemente, el principal rasgo distintivo de la LIJ sea el valor formativo-didáctico que le ha llevado, precisamente, a convertirse en un género peligroso para aquellos que la han utilizarlo de forma tendenciosa (Fernández, 2000: 232) ya que cualquier tipo de literatura ofrece una visión del mundo y, consiguientemente, trata de influir al lector con mayor o menor sutileza. La literatura es como un depósito universal donde se almacena la memoria colectiva de las obras de escritores de diversas procedencias que quisieron ponerlas a disposición de los lectores de todas las épocas, lenguas y culturas. Por eso, los lectores siempre han resultado peligrosos para los poderes autárquicos (Cerrillo, 2010: 64). En un sinfín de ocasiones, la lectura ha funcionado como instrumento de instrucción y adoctrinamiento mediante el planteamiento de modelos de conducta "correctos" o "adecuados", en especial, para los sectores más ávidos y susceptibles de copiar patrones morales, como son la infancia y la juventud.

Con el paso del tiempo, la LIJ española, como cualquier otro sistema literario, formado tanto por las aportaciones nacionales como las procedentes de textos traducidos, ha conformado unos cánones sólidos que establecen una serie de normas tácitas que tanto el escritor como el traductor se han visto obligados a respetar.

\section{La LIJ traducida del inglés en España desde la Guerra Civil española}

Históricamente, los gobiernos despóticos han manejado a su antojo el acceso a los libros como otro elemento más en su detentación del poder y control del pueblo. Esto, unido al perfil del principal destinatario y a los rasgos lingüísticos y culturales de sus obras, hacen de la LIJ una parcela especialmente vulnerable a los designios del gobernante de turno. Aupado en el poder, el régimen franquista no desaprovechó la oportunidad de aplicar un férreo control sobre la información y la educación mediante el uso de la censura como medio de encauzamiento 
ideológico. Todo tipo de material impreso y gráfico, manuales escolares, cine, teatro, prensa y literatura de todo tipo, fueron sometidos a una criba orientada a construir una imagen de la "Nueva España" según los principios del nacional-catolicismo (Sotomayor, 2005: 397).

Si la rebajada condición atribuida a la LIJ la convierte ya en un terreno proclive a la manipulación, más aún es así cuando se trata de un producto traducido. Las traducciones de LIJ tuvieron enormes trabas durante el franquismo debido a que los regímenes totalitarios tienden a resaltar el valor de lo nacional y rechazan lo procedente de fuera (Pascua, 2011: 64) ${ }^{2}$. Un estudio de gran solvencia sobre la LIJ traducida en España es el de Marisa Fernández (1996) quien, con métodos descriptivos, expone con precisión las vicisitudes de la LIJ traducida del inglés, su incorporación al sistema literario español y su influencia en el desarrollo posterior de la LIJ. No obstante, son casi inexistentes los trabajos acerca de la censura ejercida sobre las obras dedicadas al público infantil.

En este estudio, la traducción (literaria) no se entiende en su sentido tradicional, sino como un concepto semiótico, es decir, como un mecanismo de transferencia por el que unos modelos textuales de un sistema literario se traspasan a otro sistema (Shavit, 1986: 112). La traducción supone un acto comunicativo que pone en relación dos sistemas literarios (origen y meta) teniendo presente las condiciones textuales, contextuales y pragmáticas (Nord, 1997: 73) como sucede con la LIJ traducida en España durante el franquismo. La traducción no se realiza independientemente de su entorno, sino que manifiesta, más que otros actos culturales, las consecuencias de las influencias institucionales y de la moral vigente. Como afirma Fernández (1996: 94) sobre la LIJ, "en la mayor parte de los casos es imposible analizar individualmente los textos, juzgar si son traducciones, adaptaciones, versiones reducidas o simples plagios de otras traducciones, ya que es común en este tipo de obras que desaparezca el nombre del traductor". Por ello, se consideran aquí traducciones también las pseudotraducciones ${ }^{3}$, las traducciones in-

\footnotetext{
${ }^{2}$ Existen varios estudios exhaustivos sobre la censura en el cine, la narrativa (especialmente dedicada al público juvenil) y el teatro de la época franquista a cargo del grupo de investigación TRACE.

${ }^{3}$ Por pseudotraducciones se entiende "texts which have been presented as translations with no corresponding source texts in other languages ever having existed [...]" (Toury 1995: 40).
} 
directas $^{4}$, las adaptaciones y todos los textos que tengan relación con el texto original (Merino, 2002: 89). A partir del s. XIX, el sistema de la LIJ de los países anglosajones (sobre todo EE. UU. y Reino Unido) gozó de enorme prestigio y su influencia se extendió a otros países. Sus efectos se aprecian en España a partir de principios del s. XX (Fernández, 2000: 227), aunque no existen datos fiables de que más de la mitad de las traducciones de la LIJ procedían del inglés hasta los 70 (Cendán, 1986: 93). Esto, sumado a que la LIJ representaba entre el 20-40\% de la producción editorial del momento, se justifica la necesidad de analizar con mayor detalle la censura ejercida sobre aquella, en especial sobre la infantil.

\section{La censura}

Por censura se entiende la actividad practicada por la autoridad pública que limita, permite, controla, suprime, modifica o adapta ciertas obras o determinadas ideas y opiniones en los medios de comunicación social. Se justifica por motivos públicos y morales, es decir, porque tales ideas u opiniones podrían amenazar tanto la estabilidad como el bienestar de la comunidad. Elemento esencial en el concepto de censura es que la autoridad que la ejerce dispone también del poder necesario para imponer las restricciones oportunas, ya que tiene como fin inmediato reglamentar la conducta externa de los miembros de la comunidad en aras del "bien común". Se ejerce de modo discrecional por los encargados de aplicarla, normalmente personificada en la figura del censor, ya que los reglamentos no son más que una orientación general. Esto conlleva el riesgo implícito de que su labor se tiña de subjetividad y que, por tanto, los dictámenes resultantes sean volubles. Profundizar en las censuras ejercidas sobre la traducción de textos narrativos orientados al público infantil y juvenil durante el franquismo puede ayudarnos a comprender mejor la situación presente en la que seguimos consumiendo aquellas traducciones que se reeditan sin adaptación alguna para el público actual (Merino, 2002: 69).

\footnotetext{
${ }^{4}$ Es decir, aquellas realizadas a partir de la traducción de un texto original y que toman esta traducción como referente original, por lo que siguen el mismo proceso que una traducción directa o de primera mano (Toury, 1995: 42).
} 


\subsection{Recorrido legislativo por la censura de la LIJ en España}

A los efectos de este artículo, el franquismo se divide en dos etapas. El primer franquismo (1939-1955) marcado por el fin de la Guerra Civil española y la publicación del Decreto de 24 de junio de 1955 y la Orden Ministerial donde se detallan los criterios de ordenación de publicaciones infantiles (Fernández, 2000: 244). Estos años corresponden al periodo de mayor autarquismo e intervencionismo del Gobierno en todos los órdenes de la vida española. Se implantó una rígida censura previa en todas las publicaciones y la obligatoriedad de doblar al español todas las películas. En 1938 la Ley de Prensa e Imprenta tuvo en cuenta el tipo de lector al que iba dirigida para prohibir toda lectura que "siembre ideas perniciosas entre los intelectualmente débiles" (Pascua, 2011: 50). Las órdenes ministeriales de 1938 y 1939 establecieron que la publicación de cualquier material impreso sería evaluada por la Sección de Censura, que podía denegar la publicación de obras por motivos doctrinales o alegando escasez de papel, podía obstaculizar la publicación de otras obras preferentes (Pascua, 2011: 51). Esta ley fue especialmente severa para la LIJ ya que "condicionó, en cada etapa, la creación, edición, difusión y venta de libros y publicaciones destinadas a la infancia y a la juventud" (Cendán, 1986: 47-56). En 1942 se creó el Gabinete de lectura de Santa Teresa de Jesús, cuya valoración moral de las obras serviría a bibliotecas públicas y centros de enseñanza para elegir las lecturas infantiles y juveniles. La censura alcanzó su punto álgido con la creación en 1952 del primer órgano autónomo de censura para la LIJ, la Junta Asesora de Prensa Infantil (Cendán, 1986: 54). Su objetivo era informar sobre la orientación y el contenido de las publicaciones periódicas y no periódicas para niños, remitiendo sus informes al Ministerio de Información y Turismo que denegaba o autorizaba su edición. Esta junta aprobó un reglamento con las prescripciones que habían de considerarse a la hora de redactar e ilustrar obras para niños o adolescentes en referencia a cinco bloques: la religión, la moral, el punto de vista psicológico y educativo, los aspectos patrióticos y los aspectos literarios y artísticos (Cendán, 1986: 55-59).

La segunda etapa (1956-1978) vive el declive de la autarquía con el inicio del Plan de Estabilización y Liberalización (agosto de 1959). Este aperturismo trajo consigo un marcado crecimiento económico. Por ello, no extraña que en los 60 y 70 floreciera la LIJ en España como lo 
demuestra el buen número de editoriales que se dedicaron totalmente a la LIJ (Doncel, Editoral Nacional, Lumen y Noguel) y que otras muchas introdujeran obras infantiles y juveniles en su repertorio (Juventud, Molino, etc.). En 1962 se crea la Comisión Asesora de Publicaciones Infantiles integrada en la Dirección General de Información.

A partir de 1962 se reordenó la situación de la censura en España suprimiendo la obligatoriedad del doblaje. La Ley de Prensa e Imprenta de 1966 sustituye la censura oficial por el procedimiento del depósito previo de las publicaciones, aunque subsiste la posibilidad de la consulta previa. La Ley de 1966, o Ley Fraga, supuso un notable avance al suprimir la censura franquista y autorizar a las empresas editoras designar libremente al director del diario o la revista. Pese a que esta ley no afectaba directamente a la LIJ, sí que la condicionó ya que permitió el auge de la edición de LIJ en España al relajar el celo censor. Tanto fue así que tras su promulgación no se han encontrado en el Archivo General de la Administración (en lo sucesivo AGA) expedientes con prohibiciones de publicación de LIJ, sino solo algunas alteraciones textuales (Fernández, 2007: 21-22).

El último hito destacable de esta segunda etapa es la publicación del Estatuto de Publicaciones Infantiles y Juveniles (1967), como desarrollo de la Ley de Prensa e Imprenta (Cendán, 1986: 61). El último expediente revisado por la censura data de 1978 que marca el inicio de la última etapa (desde 1978 en adelante). Se caracteriza por el decaimiento del régimen, que coincide con la práctica desaparición de los mecanismos censores tradicionales tras la muerte de Franco y que llega hasta nuestros días. En la década de los 70, en pleno apogeo de la LIJ, se empieza a conceder mayor importancia a la ilustración en libros para niños (Pascua, 2011: 24). La consolidación de la LIJ como segmento literario destacado llegó en la década de los 80 suponiendo la mitad de la producción editorial comercial (Pascua, 2011: 25).

\subsection{Mecanismos censores del franquismo a nuestros días}

Todo producto cultural distribuido en España desde 1939, tanto los surgidos antes de la contienda como los nuevos, nacionales y de origen extranjero, pasaron indefectiblemente por el tamiz censor en el que quedaron, aparte de los vestigios asociados al funcionamiento político- 
burocrático, marcas de procesos textuales intermedios como la autocensura y otros tipos de adaptaciones (Merino, 2002: 70). A los pocos meses de iniciarse la Guerra Civil española, los primeros gobiernos franquistas revisaron el contenido de las bibliotecas para filtrar y "limpiar" sus estanterías en base a criterios religiosos, morales y patrióticos. Llevaron a cabo una purga selectiva de las lecturas disponibles mediante la quema de aquellos libros que no encajaban con su visión patriótica de España. Con el advenimiento del régimen de Franco, la LIJ sufrió el azote de la censura tanto en las bibliotecas públicas, donde se seleccionaron las lecturas, como con el dirigismo que sufrieron las editoriales dedicadas a la LIJ (Pascua, 2011: 23). Se defendió a ultranza lo nacional mediante el rechazo de plano de lo extranjero. Por ello, como medio para sortear la censura, los editores se sirvieron de la reedición de obras anteriores a la Guerra Civil e incluso a la República, normalmente de aventuras, que no hubieran recibido críticas del sector católico. Entre estos autores están Curwood, Doyle, Burroughs, London, etc. (Fernández, 2007: 29-30). Se creó un procedimiento por el cual toda obra que quisiera publicarse debía formalizar una solicitud de autorización que era evaluada por el censor de turno y de la que se emitía un expediente donde se dictaminaba la recomendación correspondiente. Estos expedientes se almacenaron en el AGA en Alcalá, una de las principales fuentes primarias para el estudio de la censura durante la etapa franquista.

La censura también adoptó fórmulas de prohibición personalizadas, como por ejemplo en el traductor Antoniorrobles. Sus traducciones de los cuentos de Walt Disney fueron aprobadas hasta 1941, cuando se consolidan la Dirección General de Propaganda y la Sección de Censura y se analiza más detenidamente el contenido de las obras infantiles y juveniles. Desde ese momento, Antoniorrobles se topa con todo tipo de impedimentos censorios (Sotomayor, 2005: 401). Su proclamación de los ideales republicanos y su argumentación a favor de la igualdad de derechos y del acceso a la educación le otorgó la etiqueta de "no publicable" entre la censura franquista. Elena Fortún y Salvador Bartolozzi fueron otros dos escritores sobre los que la censura cambió de opinión y cuyas publicaciones fueron torpedeadas tras el aumento de infraestructura administrativa. Las búsquedas en el AGA han permitido localizar datos sobre las traducciones de Antoniorrobles de cuentos de Walt Disney. En la caja 21/6459 se expone que 
el traductor no puede figurar en la publicación "ni percibir retribución alguna".

Fernández (2007, 2000, 1996) y Merino y Rabadán (2002: 137) distinguen tres niveles censorios aplicados sobre la LIJ durante el régimen franquista. Por las características propias de la LIJ, el primer nivel censor fue la autocensura autorial del escritor quien, al escribir estas obras teniendo presente los parámetros de aceptabilidad considerados adecuados en la época, evitaba las temáticas, roles, posicionamientos morales, etc. que pudieran suscitar el rechazo de su editor. En este primer nivel de censura, y con posterioridad a este autocontrol del escritor, entraba en juego la censura editorial (Fernández, 2000: 243), cuando detectaba que se atacaba alguno de los valores culturales, morales y espirituales del sistema (Pascua, 2011: 65). El filtro editorial actuó sobre todo durante la dictadura por motivos económicos, y como veremos, todavía hoy pervive por este motivo y por otros didácticomorales. En su afán por garantizarse el permiso de publicación de las obras de LIJ por las instituciones y una buena acogida entre el público menos experimentado, los editores supeditaron criterios como la calidad lingüística de las traducciones, la relajación excesiva de registro, la elección de temáticas no triviales y otros que, en otra época, hubieran sido irrenunciables.

Tras este doble filtro autoimpuesto desde la creación de la obra o de la traducción, se aplicaba el segundo nivel censorio mediante las disposiciones de las diversas legislaciones genéricas y específicas promulgadas durante la dictadura vistas en el apartado anterior. El tercer nivel de censura corresponde a la influencia de la Iglesia católica que asesoraba a los censores estatales sobre los principios que debían regir la idoneidad de las obras llevando incluso a reevaluar algunas obras (Fernández, 2007: 20).

\subsection{La traducción como mecanismo censor}

Dada la posición periférica que ocupa la LIJ dentro del polisistema literario, no estaba mal considerado que los traductores de estas obras manipulasen los textos modificando, ampliando, resumiendo, eliminando o añadiendo texto. No obstante, estos procedimientos translatorios estaban permitidos siempre y cuando fueran para ajustar el texto a las 
capacidades del niño lector o porque la sociedad del momento los consideraba "buenos" (Shavit, 1986: 112-113). La búsqueda de aceptabilidad del receptor en la LIJ llevó a acomodar el texto a la capacidad lectora del destinario, siendo el factor más influyente en el proceso de traducción. Consecuencia de ello son las simplificaciones léxicas y sintácticas, la utilización de fórmulas, clichés repetitivos, adaptaciones de registro e incluso la copia de modelos importados. Esto se puede apreciar en las traducciones de la magnífica serie de relatos Sapo y Sepo del escritor estadounidense Arnold Lobel, donde se pueden reconocer estas restricciones lingüísticas. Todas estas estrategias traductoras provocaron una homogeneización de las traducciones de LIJ. Sin embargo, el mecanismo censor más habitual durante la dictadura franquista, también operado vía traducción, sobre la LIJ fue la depuración del texto traducido (TT) a través de la eliminación textual (Fernández, 2000: 240), de oraciones, fragmentos e incluso párrafos completos.

Por otra parte, dado el perfil bajo habitualmente atribuido a la LIJ y argumentando motivos de orden pedagógico-moralistas prevalentes en ciertas épocas, se permitió la manipulación impune y partidista tanto del TO (texto original) como del TT para producir un texto final conforme a las preferencias del agente u organismo censor (Fernández, 2000: 243). Las adaptaciones de textos originales y traducidos para sortear las trabas censoras fueron caprichosas y volubles, dependientes de la arbitrariedad del censor de turno. En suma, hablar de traducción de LIJ durante el periodo analizado es abrir la puerta a la posible manipulación mediante los diversos mecanismos traductores. Intervencionismo que siempre se planteó como el medio que permitía conseguir la deseada aceptabilidad a ojos del público objetivo.

\subsection{Algunos ejemplos de intervenciones vía traducción}

Las únicas pruebas documentales de los efectos de la censura son los expedientes del AGA. En numerosas ocasiones, son meros comentarios sobre la calidad lingüística sin alusión a la traducción. Son aún más escasas las evidencias conservadas de las acciones censoras ejercidas sobre la LIJ, especialmente sobre la infantil, debido al reducidísimo número que se tradujo durante la dictadura. Mayoritariamente, las traducciones se rigieron por criterios comerciales centrándose en la LIJ de 
masas dirigida a un público juvenil y abordando temáticas de evasión, tipo novela de aventuras, para no suscitar suspicacias en los filtros censores.

Un caso paradigmático en el estudio de las traducciones anglosajonas de LIJ censuradas es la obra de Richmal Crompton. Su serie sobre William (Guillermo en España) obtuvo un tremendo éxito tanto en el mercado anglosajón como español. El director de la editorial Molino, J. M. Huertas Ventosa, publicó la serie de Guillermo en España. Un año antes de estallar la Guerra Civil publicó Travesuras de Guillermo y Los apuros de Guillermo, pero desde 1940 importó las traducciones publicadas en Argentina (Pascua, 2011: 71).

El exhaustivo estudio de Marisa Fernández (1996) sobre la LIJ traducida en los archivos del AGA y el análisis de Isabel Pascua (2011) sobre la serie de Guillermo nos brindan datos reveladores sobre las traducciones de esta serie de Crompton. Posiblemente, el título con mayor número de intervenciones de la primera etapa de este estudio es JustWilliam (1922) (Travesuras de Guillermo, 1942). Hipkiss (1935) realizó las primeras traducciones de esta serie y Peraire del Molino (1959) a partir de los años cincuenta. La práctica editorial habitual con las traducciones españolas de la LIJ fue utilizar la primera versión sin revisar para sucesivas reediciones.

Fernández (1996), en un análisis contrastivo de las traducciones de Just-William, detectó notables diferencias entre las traducciones de Hipkiss y las de Peraire. Mientras que Peraire mostró más respeto por la longitud del TO, Hipkiss fue más dado a las amplificaciones textuales. En Just-Williams se han hallado 105 pasajes con amplificaciones y otros 51 fragmentos con eliminaciones textuales de diversos niveles (1996: 230), datos que demuestran la manipulación a la que se sometió. Una eliminación especialmente significativa por su extensión (Fernández, 1996: 231, 2000: 241) es la siguiente: 


\begin{tabular}{|c|c|}
\hline TO & $\mathrm{TM}$ \\
\hline 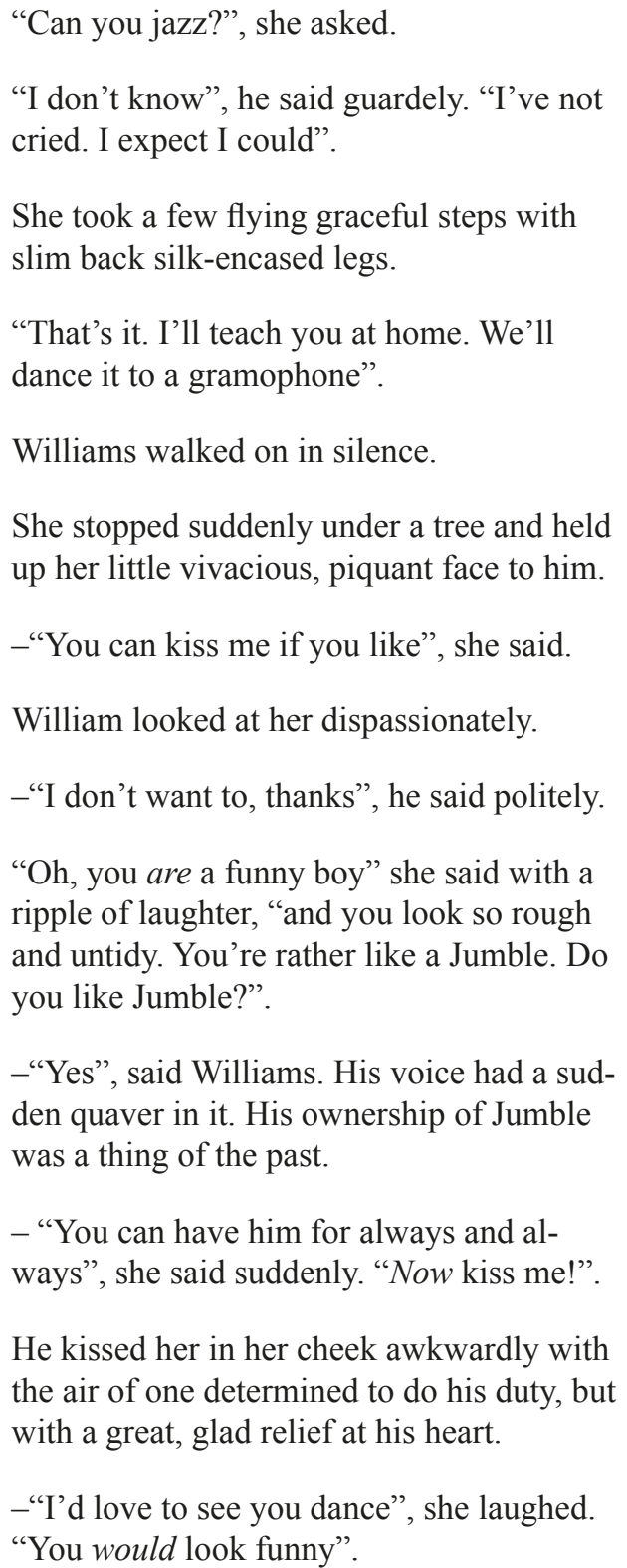 & $\begin{array}{l}\text { - ¿Sabes bailar jazz? -pregun- } \\
\text { tó aún la niña. } \\
\text {-No lo sé -respondió él, con } \\
\text { cautela-. No lo he probado } \\
\text { nunca. Supongo que sí sabré. } \\
\text { Ella dio unos cuantos pasos } \\
\text { llenos de gracia. } \\
\text {-Eso es jazz. Te enseñaré en } \\
\text { casa. Lo bailamos al son del } \\
\text { gramófono. } \\
\text { Guillermo caminó en silen- } \\
\text { cio. } \\
\text {-Me encantaría verte bailar } \\
\text {-rió Ninette, al poco rato-- } \\
\text { ¡Estarías la mar de raro! }\end{array}$ \\
\hline
\end{tabular}


Aunque no existen evidencias documentales, esta eliminación se debe posiblemente a la censura (Fernández, 1996: 231). La supresión del pasaje del beso iría contra la moral y el decoro que preconizaba la influyente Iglesia católica. Nos inclinamos a pensar que no se trata de una censura explícita motivada por un expediente censor, sino que más bien podría deberse a una autocensura editorial de la primera edición, pues para las editoriales era vital que las primeras ediciones no tuvieran mácula alguna para la censura y así conseguir la autorización para reeditarlas sin trabas. Ahora bien, los comentarios de los censores hallados en los expedientes del AGA sobre las obras de Crompton ejemplifican los vaivenes que experimentó el celo censor desde los años 30 hasta finales del siglo $\mathrm{XX}^{5}$.

Otra obra de Crompton con numerosas manipulaciones censoras en en su traducción fue la obra Still William como se aprecia en el título. En los años 40, la editorial Molino Argentina publicó el libro Guillermo el organizador pero, como advirtieron en la editorial Molino España, en la península correspondió prácticamente (incluyendo seis capítulos) a Guillermo y el cerdo premiado. La primera obra recibió sendos informes negativos para su publicación en 1943 y 1949, mientras que el segundo título pasó fácilmente la censura en 1956 (Pascua, 2011: 94). Pascua (2011) analiza los seis capítulos que pasaron del censurado Guillermo el organizador al permitido Guillermo y el cerdo premiado, buscando ejemplos de censura, de lo que se demuestra prolijo. Aparentemente, el primer filtro censor que se aplicó para salvar Guillermo el organizador fue suprimir las referencias religiosas a la iglesia protestante. Se cambiaron los términos obispo y pastor por ministro y pastor, supuestamente por autocensura editorial (Pascua, 2011: 97),

\footnotetext{
${ }^{5}$ En un primer momento, los expedientes son positivos. En el expediente 1105/40 se autoriza la impresión de 1000 ejemplares de Guillermo hace de las suyas en Molino Argentina de la "nueva serie de aventuras de Guillermo tan amenas y graciosas como las anteriores". El expediente 832/40 autoriza la importación de 1.000 ejemplares de Guillermo el Conquistador (Fernández, 2007: 33). A partir de 1942, la opinión de la censura cambia como se aprecia en el expediente 6-515/42 sobre Guillermo el Proscrito: "Cuento inglés de carácter infantil". El mismo censor, al día siguiente emite otro informe en el que lo califica de "Cuento infantil de marcado carácter inglés que desentona con la formación de nuestra infancia por lo que estimamos no deber ser autorizada" (Fernández, 2007: 34).
} 
como se aprecia en un extracto de Still William cotejado con la versión española: ${ }^{6}$

\begin{tabular}{|l|l|}
\hline \multicolumn{1}{|c|}{ TO } & \multicolumn{1}{|c|}{ TM } \\
\hline $\begin{array}{l}\text { Miss Lomas, with a good deal of con- } \\
\text { fusion, launched into a not very clear } \\
\text { account of the institution of Saint Valen- } \\
\text { tine's Day. }\end{array}$ & $\begin{array}{l}\text { La señorita Lomas, algo confusa, } \\
\text { se puso a explicar con bastante } \\
\text { poca claridad la institución del } \\
\text { día de San Valentín. }\end{array}$ \\
$\begin{array}{l}\text { "Well, I don't think much of him's a } \\
\text { saint", was William's veredict, as he } \\
\text { took out another nut and absentmind- } \\
\text { edly cracked it, “writin' soppy letters } \\
\text { to girls instead of gettin' martyred } \\
\text { prop'ly like Peter an' the others". }\end{array}$ & $\begin{array}{l}- \text { - Y escribía cartas de amor a } \\
\text { las muchachas? }\end{array}$ \\
$\begin{array}{l}\text { Miss Lomas put her hand to her head. } \\
\text { La señorita Lomas se llevó la } \\
\text { mano a la cabeza. }\end{array}$ \\
\hline
\end{tabular}

Coincidimos con Pascua (2011: 99) al suponer que esta supresión de contenido la realizó el editor o el censor debido al tratamiento mordaz del santo de la Iglesia católica. Otro caso de supresión textual se encuentra en estas líneas:

\begin{tabular}{|l|l|}
\hline \multicolumn{1}{|c|}{ TO } & \multicolumn{1}{|c|}{ TM } \\
\hline "What do people mean by sayin' they'll & - - Qué quiere decir la gente \\
send Valentine, Mother?" said William & cuando dice que va a mandar una \\
that evening. "I thought he was sort of & "valentina", mamá? -preguntó \\
saint. I don't see how you can send a & Guillermo aquella noche-. Yo \\
saint to anyone, specially when he's & creí que era un santo. No veo yo \\
dead 'n' in the Prayer Book". & cómo se le puede mandársele un \\
& santo a nadie. \\
\hline
\end{tabular}

La eliminación de la referencia a la "muerte" del santo obedece probablemente a la visión católica de la inmortalidad de estos (Pascua, 2011: 100) y pudo ser aplicada por la autocensura autorial o editorial, por el censor estatal, o por consejo de la Iglesia católica.

\footnotetext{
${ }^{6}$ La versión española es la de Espasa de 1999 de Guillermo y el cerdo premiado.
} 
En referencia al sexo femenino y al amor (Pascua, 2011: 108):

\begin{tabular}{|l|l|}
\hline \multicolumn{1}{|c|}{ TO } & \multicolumn{1}{|c|}{ TM } \\
\hline $\begin{array}{l}\text { Miss Dobson was very young and } \\
\text { very pretty. She had short golden } \\
\text { curls and blue eyes and small teeth } \\
\text { and an attractive smile. }\end{array}$ & $\begin{array}{l}\text {-La señorita Dobson era muy joven } \\
\text { rado y rizado, ojos azules, dientes } \\
\text { menudos y blancos y una sonrisa } \\
\text { muy simpática. }\end{array}$ \\
\hline
\end{tabular}

Se trata de una sustitución de un término más explícito por otro más acomodado al decoro exigido por la moral imperante. Una modulación que rebaja la sexualidad y que pudo ser introducida por cualquiera de los filtros censores anteriormente citados.

Otro de los fenómenos editoriales de procedencia anglosajona durante la dictadura fue la obra de Enid Blyton. Su marcado cariz ultraconservador se manifestaba en las abundantes alusiones xenófobas en sus textos. Esto provocó que, pese al éxito obtenido entre el público juvenil, el sector adulto vetara sus publicaciones. Las traducciones españolas de Blyton toman la primera edición del TO como texto fuente y presentan fragmentos donde se aprecia intervención en las traducciones. Por ejemplo, en el relato de 1950 Five Fall into adventure, de la serie "Los Cinco", existe una amplificación textual por parte del traductor.

\begin{tabular}{|l|l|}
\hline \multicolumn{1}{|c|}{ TO } & \multicolumn{1}{|c|}{ TM } \\
\hline $\begin{array}{l}\text { "Well, all I can say I hope I haven't } \\
\text { her layers of dirt and her sm-" she } \\
\text { began angrily. }\end{array}$ & $\begin{array}{l}\text {-Lo único que puedo decir es que } \\
\text { espero no llevar la capa de mugre } \\
\text { que tiene, ni oler tan mal...,-empe- } \\
\text { zó a replicar con enfado. }\end{array}$ \\
\hline
\end{tabular}

Como apunta Fernández (2000: 248), la cultura española no tenía ninguna objeción a que se tratase de forma ofensiva a este grupo social, por lo que esta amplificación, que si se hubiera aplicado a otro colectivo jamás habría pervivido, vio la luz sin problemas?

\footnotetext{
${ }^{7}$ Los autores susceptibles de ser analizados en busca de posibles rastros de censura no se limitan a los aquí citados. La lista tendría obligatoriamente que incluir a Twain, London, Doyle, Alcott, Burroughs, Kipling, Dahl y otros.
} 
Un ejemplo actual es el caso de la censura de la obra And tango makes three (2005) de Justin Richardson y Peter Parnell, traducida al español por la editorial Serres (Tres con Tango, 2006). Se trata de un álbum magníficamente ilustrado por Henry Cole que cuenta la historia real de una pareja de pingüinos del zoo de Nueva York, Roy y Silo, ambos machos, que desarrollan una relación de pareja. Ante esto, el guardián del zoológico, Rob Gramzay, les brinda la oportunidad de formar una familia dándoles un huevo de otra pareja. Así nació Tango, una hembra, que la pareja de pingüinos crió como si fuera su hija. Esa alusión a las relaciones homosexuales le supuso al libro una censura soterrada en EE. UU. por parte de las instituciones y asociaciones diversas. Por ejemplo, la American Library Association (ALA) elabora cada año la lista de los diez libros con mayor número de peticiones para ser retirados de las bibliotecas públicas, en un intento institucional de censurar esas obras. Uno de los libros que han encabezado esa lista en los últimos años ha sido And tango makes three. Esto ha provocado que la obra haya sido convenientemente reubicada en las bibliotecas en secciones recónditas o incluso a salas de acceso restringido para el público general. En España, sin embargo, la censura actual no adopta mecanismos tan patentes como la elaboración de libros prohibidos, sino que se manifiesta mediante fórmulas veladas. Retrasando la traducción del original (p.e. la traducción de El guardián entre el centeno, publicado en Norteamérica en 1951, que no vio la luz en España hasta bien entrados los años setenta), limitando la tirada y distribución de un ejemplar o simplemente excluyéndolo de las listas de lecturas recomendadas elaboradas por entes públicos o privados.

Otro ejemplo de traducción retardada, también sacado de entre los libros que encabezan la lista de libros prohibidos de la ALA (8. ${ }^{\circ}$ en $2005,1^{\circ}$ en 2012), es la traducción de la obra Captain Underpants que inicia serie escrita por Dav Pilkey. Se trata de una serie que narra las historias de niños de cuarto grado que, según la ALA, utilizan un lenguaje ofensivo, tienen un contenido sexual explícito y no son adecuados para niños de esas edades. Tras ser publicado en EE. UU. en 1997, hubo que esperar al año 2002 para que la editorial SM publicara la primera edición en España en su colección el Barco de Vapor, en la serie azul, dirigida a niños entre 7 y 9 años. La serie lleva vendidos más de 30 millones de ejemplares. 


\section{Consideraciones finales}

Pese al perfil bajo teóricamente atribuido a la LIJ, el régimen franquista la trató como un género de primer orden dado el poder que atesora como medio de dirigismo y control de masas. El didactismo maniqueísta que el regimen operaba a través de la censura en la LIJ le permitió instruir a los menores en su ideología. La consideración de la LIJ como literatura menor, su finalidad didáctica y su bajo estatus han justificado los grandes abusos que ha sufrido, siempre esgrimiendo que se realizaban en beneficio de la infancia (Fernández, 2000: 232).

Como se puede apreciar en los ejemplos vistos, el fomento de la autocensura autorial y editorial y la eliminación textual o la adaptación de ciertos párrafos son los principales mecanismos empleados por la censura sobre la LIJ durante la dictadura franquista. Sin embargo, estas intervenciones censoras fueron fluctuantes y caprichosas y se aplicaron con mayor o menor virulencia dependiendo del censor de turno y de la legislación vigente. Esta variabilidad de los dictámenes se observa en el repentino y drástico cambio de parecer del censor de la obra de Crompton Guillermo el Proscrito quien un día la autoriza para al día siguiente prohibirla. Este caso encarna como ninguno la volubilidad del criterio censor de la dictadura sobre la LIJ que se aplicó arbitrariamente.

En vista de lo expuesto, uno podría pensar que la censura ejercida sobre la LIJ durante el franquismo murió con el regimen y que, en la actualidad, no se da ningún tipo de control de las clases dirigentes sobre el acceso a la literatura y a la información. Nada más lejos de la realidad (Fernández, 2000: 252) ya que las lecturas hoy destinadas a niños siguen conteniendo una gran carga ideológica (Pascua, 2011: 117). Pero en los últimos años, los criterios y mecanismos de censura han sufrido una notable evolución. La utilización de temáticas antaño consideradas ofensivas para el recato debido, como el sexo o las expresiones de registro informal o incluso vulgar, ya no se ven como un motivo de exclusión de las obras dirigidas a niños. La censura actual ha adoptado otras fórmulas más sofisticadas y menos visibles. Sin embargo, el motivo esgrimido sigue siendo el mismo que utilizado siglos atrás: utilizar la LIJ con una función didáctico-moralizante, a lo que se añaden otros motivos actuales como la discriminación racista o religiosa o lo "políticamente correcto". Bajo esta etiqueta se enmascaran las ya conocidas estrategias de autocensura autorial y editorial que siguen 
estando, lamentablemente, vigentes en la actualidad. En estos dos frentes se mueve el debate sobre los límites de la aceptabilidad de la LILJ. Por una parte, en el plano autorial, el escritor se plantea dónde están las fronteras morales de las temáticas que el intermediario (familia, instituciones, etc.) aceptará como adecuados para sus hijos. Por otra parte, en el plano empresarial, las editoriales barajan esos mismos criterios morales que buscan preservar la inocencia de la infancia y la juventud y, al mismo tiempo, sopesan las probabilidades de éxito de venta del libro en la sociedad actual.

El boom de la LIJ es un hecho innegable y, dentro de esta, la LIJ traducida representa casi la mitad de la producción total ${ }^{8}$. Ahora, como plantea, Maite Carranza ${ }^{9}$, el debate sobre los límites de la LIJ está abierto y la polémica servida.

\section{Bibliografía}

Cendán Pazos, Fernando. 1986. Medio siglo de libros infantiles y juveniles en España (1935-1985). Madrid: Ediciones Pirámide.

Cerrillo Torremocha, Pedro César. 2010. Sobre lectura, literatura y educación. México: Miguel Ángel Porrúa.

Díaz Armas, Jesús. 2008. La imagen en pugna con la palabra. Saber e educar 13: 43-57.

Even-Zohar, Itamar. 1979. Polysystem Theory. Poetics Today 1(1-2, Autumn): 287-310.

Fernández López, Marisa. 1996. Traducción y Literatura Juvenil (narrativa anglosajona contemporánea en España). León: Universidad de León.

Fernández López, Marisa. 2000. La traducción de textos infantiles y juveniles anglosajones y la censura franquista. En Rabadán, R. (ed.) Traducción y censura inglés-español: 1939-1985. Estudio preliminar. León: Universidad de León, 227-253.

\footnotetext{
${ }^{8}$ Según datos publicados por el Ministerio de Educación y Cultura la proporción de obras traducidas dentro del volumen total de la LIJ representó nada menos que el 46,9\% del total. Consúltese el documento en el sitio web: http://www.mecd.gob.es/cultura$\mathrm{mecd} / \mathrm{dms} / \mathrm{mecd} /$ cultura-mecd/areas-cultura/libro/mc/observatoriolect/redirige/estudios-e-informes/elaborados-por-el-observatoriolect/TRADUCCION_2010.pdf

${ }^{9}$ Escritora catalana (Barcelona, 1958) ganadora del Premio Nacional de Literatura Infantil y Juvenil 2011 por su obra en catalán Paraules emmetzinades (Palabras envenenadas, Edebé), la primera novela para jóvenes que trata de una manera abierta y clara, aunque sin recrearse, el tema de los abusos sexuales infantiles. http://www.mecd.gob.es/lectura/pdf/v12_maite_carranza.pdf
} 
Fernández López, Marisa. 2007. Comportamientos censores en la literatura infantil y juvenil traducida del inglés en la época franquista: Establecimiento de un corpus textual. En Merino, R. (ed.) Traducción y censura en España (1939-1985). Estudios sobre corpus TRACE: cine, narrativa, teatro. Bilbao: Universidad del País Vasco/Universidad de León, $19-48$.

Merino Álvarez, Raquel. 2002. Traducciones censuradas de teatro y literatura infantil y juvenil en la España de Franco. En Lorenzo, L.; Pereira, A. \& Ruzicka, V. (ed.) Contribuciones al estudio de la traducción de literatura infantil y juvenil. Dossat, Madrid, 69-90.

Nord, Christiane. 1997. Translation as a Purposeful Activity. Mánchester: St. Jerome.

Pascua Febles, Isabel. 2011. La literatura traducida y censurada para niños y jóvenes en la época franquista: Guillermo Brown. Las Palmas de Gran Canaria: Universidad de Las Palmas de Gran Canaria.

Puurtinen, Tina. 1989. Assessing Acceptability in Translated Children's Books. Target 1(2): 201-213.

Shavit, Zohar. 1986. Poetics of Children's Literature. Atenas: University of Georgia Press.

Sotomayor Sáez, María Victoria. 2005. Censura y libros para niños tras la guerra civil española. En Ruzicka, V.; Vázquez, C. \& Lorenzo, L. (ed.) Mundos en conflicto: representación de ideologías, enfrentamientos sociales y guerras en la literatura infantil y juvenil. Vigo: Universidad de Vigo, 397-412.

Toury, Gideon. 1995. Descriptive Translation Studies and Beyond. Ámsterdam-Filadelfia: John Benjamins. 